\title{
Hands-on Optics training courses for school teachers
}

\section{Manuel M. Costa, José Vazquez-Dorrio}

Manuel F. M. Costa, José B. Vazquez-Dorrio, "Hands-on Optics training courses for school teachers," Proc. SPIE 9666, 11th Education and Training in Optics and Photonics Conference, $96660 \mathrm{~N}$ (5 June 2009); doi: $10.1117 / 12.2207973$

SPIE Event: Eleventh International Topical Meeting on Education and Training in Optics and Photonics, 2009, St. Asaph, United Kingdom 


\title{
HANDS-ON OPTICS TRAINING COURSES FOR SCHOOL TEACHERS
}

\author{
Manuel F. M. Costa*, José B. Vazquez-Dorrio** \\ *Universidade do Minho, Departamento de Física \\ Campus de Gualtar, 4710-057 Braga \\ Portugal \\ Tel. +351253 604070; Fax. +351253678981 \\ e-mail: mfcosta@fisica.uminho.pt; \\ **Universidad de Vigo, Escuela de Ingenieros de Minas, Departamento de Física \\ Lagoas, Campus de Marcosende, Vigo, Galicia \\ Spain \\ e-mail: bvazquez@uvigo.es
}

\begin{abstract}
For long time optics' scientists all around the world realised the importance to the development of optics of providing our school students a good effective education in optics. A large range of quality educational support materials was developed and is readily available. Fortunately this is also true in what concerns materials to be used in hands-on experiments based learning covering virtually all fields of optics and also intended or adapted for use at all school levels. Recent trends in educational policies are given science education an increasing importance within school' curricula. Furthers efforts must be developed in order to increase the importance of optics in school syllabus and generalize it throughout all school levels, while guaranteeing a quality effective education. This demands a strong focus on an active investigative hands-on experiments based study of the different subjects of light and optics by the students at the classroom in formal context but also in different informal activities. In this process the role of the teacher is of crucial importance. Quite often, however, teachers are not adequately trained in this type of pedagogic approach and frequently feel the need of further training in these issues but also on the recent advances of optics and photonics. In other to tackle this need a number of different training courses for school teachers, from pre-school to highschool and vocational training schools, were designed and will be presented and discussed in this communication.
\end{abstract}

Eleventh International Topical Meeting on Education and Training in Optics and

Photonics, edited by K. Alan Shore, Deb Kane, Proc. of SPIE Vol. 9666, 96660N

(C) 2009 SPIE, OSA, IEEE, ICO · doi: 10.1117/12.2207973 


\section{Introduction}

Science teaching at all school levels should be generalised and rendered more effective in order to guarantee a strong and sustainable improvement of Science and its technological applications while improving and extending scientific literacy in our societies [1]. All over the world this is being, fortunately, accepted by governments and civil society institutions. Europe calls for more Science and Technology graduates trying to achieve the targets set in Lisbon Strategy to make the European Union "the most dynamic and competitive knowledge-based economy in the world capable of sustainable economic growth with more and better jobs and greater social cohesion, and respect for the environment by 2010" [2-5].

These demands add increasing pressure to the school and to school' teachers. Science teachers in particular face higher demands. In these troubled times students, and teachers themselves (all of you in fact...), can hardly foresee a future coherent career, teachers must find ways of attract [6] and engage the students into the learning process. Informal and non-formal activities can have a very positive impact $[7,8]$ but in-classroom activities are fundamental and here a hands-on investigative experiments based active learning is fundamental [9]. Unfortunately frequently our science teacher were trained in an essentially theoretical way and are not used to perform experiments and even less to induce or even allow the students to act hands-on, not being taught to understand the process or trained for it.

Light, Optics and Photonics have a crucial importance in our lives and to the prospects of development of our world with breathtaking developments in many different fields, including fiber optics sensor and communications, image acquisition and processing, lasers, photodynamic therapy, real time holography, optical computing, solar energy conversion and light sources...

On these lines we have developed and are running training courses [10] on hands experiments teaching approaches. The general objectives of these Hands-on Optics, supported by the European Commission (Life Long Learning/ Comenius action) are to provide schoolteachers from basic to secondary and vocational schools strong effective knowledge on the basics of optics, focusing on an intensive training in the execution of hands-on experimental activities on the major optics subjects. Hands-on/minds-on skills will be developed allowing the teachers to organise experimental activities in their class in a confident and effective way. 


\section{Methodology}

The early as possible in their education the students should introduced to and get acquainted with basic optics concepts as those related to the nature of light, the subjects of general optics, geometrical physical and quantum, but also with advanced subjects of utmost importance and actuality as wave guidance, fibre optics and telecommunications, image digitalization and processing, light production and energy conversion, optical processing and computing,...

Not only specific knowledge must be acquired but also and specially the ability of exploring reasoning, acting interactively to be able to find, analyse and solve new interdisciplinary problems, should be explored and enhanced as extensively as possible.

The best way of achieving an effective sound education of the students on these optics issues is by inducing the students to an active committed participation in the teaching/learning process, through investigative practice and experimentation, making use of the new instruments and resources of the Information Society. Although a strong focus should be put into these hands-on approaches the theoretical perspective should not be forgotten and introspective abstract reasoning activities should be allowed, in particular if the characteristics of a student or group of students advise it. Constructivism [11] construcionism [12] and conceptual learning [13] among many other approaches should be explored.

\section{The structure of Hands-on Optics training course}

Although there will be a theoretical introduction to the theme, the course's methodology will essentially be based on practical experimental activities hands-on/minds-on, followed by reflection and discussion. There will be a final assessment/evaluation session.

The pedagogic approach we suggest to be used relies on a functional integration of different pedagogical theories and practices namely the constructivism, conceptual learning and pro-active learning by hands on experimentation and research. Responsibility, critical reasoning and observation, method and flexibility, interdisciplinarity, volunteer self-rewarding commitment, joint efforts and teamwork, are the main keywords that should guide all pedagogical activities. Making use of the new instruments and resources of the Information Society. 
The week long training course is mostly practical and strong personal interaction among the students (the physics and science teachers) and with the trainers and tutors is expected and will be encouraged (enforced...).

We expect the teachers to act as students also in order for them to better understand the problems difficulties and behaviours of their own students.

Apart from the main curricular optics subjects we introduce lectures and workshop on transversal issues like motivational tools and activities including the resource to non-formal or informal activities. Computer modelling and simulation tools can be very useful in helping complementing or even inducing hands-on experimental works. Often teachers work "alone" and feel that way.

The establishment of cooperation mechanisms among schools and teachers from the same environment but especially when coming from different countries and cultures [14] may be very important for the teachers and individuals but also as educators. This issue will also be explored specially addressing the possibilities in the frames of the European Union foreseeing other opportunities (Erasmus Mundus like for instance).

The preparation for the course is considered important $[15,16]$. The participants receive in advance two Guides for Hands-on Experimental Activities and the Teacher's Handbook, which contains a theoretical presentation on General Optics $[17,18,19]$. One of the guides includes 42 experiments, all to be explored during the course, divided into main topics and graded from elementary to secondary level. The other guide call "Continuous" provides a series of observation based investigative activities covering basic light and optics concepts presented in an essentially nonguided way. The essential idea here is not to "show" or present an experiment but yes to induce the discovery process [17].

The follow-up of the course participants is considered of the highest importance. Enquiries and quizzes will be delivered to the teachers, together with support material to be filled by the teachers themselves and their students for a period no shorter than 3 years, to be returned to the course organiser for analysis and statistical treatment. Further training courses on more advanced topics will be made available in a near future [20]. On the other hand we expect the participants to enrol and be active members of the Hands-on Science Network were they will find a mutually supporting and nourishing ground [20].

In figure 1. we show the schedule of the two Hands-on Optics training course run in 2009 in Spain and Portugal [10]. 


\title{
$1^{\text {st }}$ Training Course on Hands-on Optics, April 3 to 11, 2009, Vigo, Pontevedra, Spain \& $2^{\text {nd }}$ Training Course on Hands-on Optics, September 3 to 11, 2009, Braga, Portugal
}

\author{
Syllabus: \\ 1 st day \\ 18:00 Registration

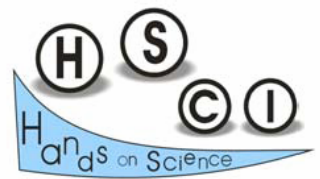 \\ 2nd day \\ 9:30 Opening and presentation, M. F. Costa \\ 10:00 Optics. Past, present and future B. Dorrio, D. Sporea, M. F. Costa, \\ 11:30 Hands-on science P. Michaelides \\ 14:30 Introduction to optics. The basics I. M. F. Costa, B. Dorrio, P. Michaelides \\ 17:00 Discussion \\ 3rd day \\ 9:30 Constructivism. Theory and practice I S. Gatt \\ 11:30 Constructivism. Theory and practice II S. Gatt \\ 14:30 Introduction to optics. The basics II. M. F. Costa, B. Dorrio, P. Michaelides \\ 18:00 Discussion \\ 4th day \\ 9:30 Introduction to optics. The basics III. M. F. Costa, B. Dorrio, P. Michaelides \\ 14:30 How to organise a hands-on experiments class. The scientific method P. Michaelides \\ 16:30 Safety issues D. Sporea \\ 18:00 Discussion \\ 5th day \\ Free day. Visits to local schools and interaction with local teachers and students \\ 6 st day \\ 9:30 Hands-on activities I. The nature of light. B. Dorrio, C. Lima, M. F. Costa \\ 14:30 Hands-on activities II. Color and vision. N. Tsaglotis, J Fernandes, M. F. Costa \\ 16:30 Hands-on activities III. Reflection and refraction. J Fernandes, N. Tsaglotis, M. F. Costa \\ 18:00 Discussion \\ 7 th day \\ 9:30 Hands-on activities IV. Ray tracing. M. F. Costa, R. Batista \\ 11:30 Hands-on activities V. Prims lenses and mirrors. J. Fernandes, C. Lima, M. F. Costa \\ 14:30 Hands-on activities VI. Fiber optics, polarisation, diffraction, holography. M. F. Costa, N. Tsaglotis, C. Lima \\ 18:00 Discussion \\ 8th day \\ 9:30 "Funny" optics. Ideas for Science Fairs. M. F. Costa, P. Michaelides, B. Vasquez \\ 11:00 Computer simulation on Microsoft Excel. V. Fonseca \\ 14:30 Comenius EU School' cooperation projects. M. F. Costa, P. Michaelides \\ 16:30 Course' evaluation and conclusion \\ 19:30 Farewell dinner \\ 9th day \\ Departure
}

(Every day: Coffee break - 11:00 and 16:00; Lunch 12:30; 19:30 Dinner)

Trainers: Professor M. F. M. Costa (University of Minho), Professor B. Dorrio (University of Vigo), Professor P. G. Michaelides (University of Crete), Professor S. Gatt (University of Malta), Dr. D. Sporea (NIPNE), Prof. V. Fonseca (University of Minho). Tutors: Dr. N. Tsaglotis, Dr. R. Batista, Dr. C. Lima, Dr. J. Fernandes.

Figure 1. Program of the "Hands-on Optics" training course 


\section{Conclusion}

The development of optics and photonics requires a large number of well prepared highly motivated scientist and technicians that should be teach and trained as early and as efficiently as possible in a positive rewarding environment. The new stringent requirements of the modern society demand not only the gathering of specific knowledge but also and specially of the competencies the ability of acting interactively to be able to find, analyze and solve new interdisciplinary problems. The best way of achieving an adequate formation of our students on these issues is by inducing the students to an active committed participation in the teaching/learning process, through hands-on investigative practice and experimentation.

Teacher training activities on the hands-on investigative experiments based learning of optics in all school levels and in informal contexts should widely promoted and disseminated.

\section{References}

1. "Hands-on Science"; Costa MFM; Selected Papers on Hands-on Science (ISBN 978-989-953362-2); Costa MF, Dorrío BV, Michaelides P and Divjak S (Eds.); Associação Hands-on Science Network, Portugal; pp. 1-13 (2008).

2. European Commission, White paper on education and training: Teaching and learning-Towards the learning society (White paper), Office for Official Publications in European Countries, Luxemburg, 1999

3. European Commission, (2004), Europe needs More Scientists: Report by the High Level Group on Increasing Human Resources for Science and Technology. Brussels: European Commission.

4. European Commission, (2007), Science Education Now: A renewed pedagogy for the future of Europe, Brussels: European Commission Directorate-General for Research Information and Communication Unit.

5. Lisbon European Council, 23 and 24 March 2000, Presidency Conclusions, (http://www.europarl.eu.int/summits/lis1_en.htm)

6. "Optics and Pool: Play the Game"; Lima CFS and Costa MFM; Selected Papers on Hands-on Science (ISBN 978-989-95336-2-2); Costa MF, Dorrío BV, Michaelides P and Divjak S (Eds.); Associação Hands-on Science Network, Portugal; pp. 182-185 (2008). 
7. "Proceedings of the 5th International Conference on Hands-on Science. Formal and Informal Science Education", ed. Manuel F. M. Costa, Jose B. Vazquez-Dorrio, Mikiya Muramatsu e António Pavão, ISBN 978-989-95095-3-5, pp. 274, September 2008.

8. Zita Esteves, Andreia Cabral, Manuel F. M. Costa, "Informal Learning in Basic Schools. Science Fairs", Int. J. Hands-on Science; vol. 1, no. 2, pp. 23-27 (2008).

9. "Selected Papers on Hands-on Science", ISBN 978-989-95336-2-2, Costa MF, Dorrío BV, Michaelides P and Divjak S (Eds.); Associação Hands-on Science Network, Portugal pp. 699, July 2008.

10. https://webgate.ec.europa.eu/llp/istcoursedatabase/index.cfm?fuseaction=DisplayCourse\&cid=74 12

11. Gatt S, Constructivism - An effective Theory of Learning, in Gatt $S$ and Vella $Y$ (Eds.), Constructivist teaching in Primary School Social Studies, Mathematics, Science, ICT, Design and Technology, Agenda Publishers, Malta, 2003.

12. "A Study of Educational Robotics in Elementary Schools"; Ribeiro C, Coutinho C, Costa MFM and Rocha M; Selected Papers on Hands-on Science (ISBN 978-989-95336-2-2); Costa MF, Dorrío BV, Michaelides P and Divjak S (Eds.); Associação Hands-on Science Network, Portugal; pp. 580-595 (2008).

13. "Teaching Physics Modelling with Graphic Simulations Tools"; Zamarro JM, Molina GJ and Núñez MJ; Selected Papers on Hands-on Science (ISBN 978-989-95336-2-2); Costa MF, Dorrío BV, Michaelides P and Divjak S (Eds.); Associação Hands-on Science Network, Portugal; pp. 6973 (2008).

14. Sjoberg, S.\& Schreiner, C., (2005), How do learners of different cultures relate to Science and Technology? Results and Perspectives from the ROSE Project, Asian-Pacific forum on science learning and Teaching, Volume 2, Issue 6, Forward p.2.

15. Dorrío BV, Rúa A, Soto R and Arias J, Hands-on Physics Bibliography, Proceedings of the 1st International Conference on Hands-on Science, Teaching and Learning in the XXI Century, Divjak S (Ed.), 2004 July 5-9, Ljubljana, Slovenia, University of Ljubljana, pp.: 119-124, 2004.

16. UNESCO, 700 Science experiments for everyone, Doubleday: New York, 1962.

17. Manuel F.M. Costa, Hands-on Introduction to Optics / Introdução à Óptica (bilingual edition), Hands-on Science Network, ISBN 989950952 3, September 2006. 
18. "Learning Optics at Basic Schools by Experimentation"; Costa MFM; Selected Papers on Handson Science (ISBN 978-989-95336-2-2); Costa MF, Dorrío BV, Michaelides P and Divjak S (Eds.); Associação Hands-on Science Network, Portugal; pp. 25-28 (2008).

19. "Introduction to Fiber Optics and Telecommunications"; Costa MFM; Selected Papers on Handson Science (ISBN 978-989-95336-2-2); Costa MF, Dorrío BV, Michaelides P and Divjak S (Eds.); Associação Hands-on Science Network, Portugal; pp. $492-496$ (2008).

20. www.hsci.info 